\title{
EDITORIAL
}

\section{IBICT: 51 anos}

O Instituto Brasileiro de Bibliografia e Documentação (IBBD), criado por meio do decreto n⿳⼈ 35.124, de 27 de fevereiro de 1954, foi transformado no atual Instituto Brasileiro de Informação em Ciência e Tecnologia (Ibict), por meio da Resolução no 20/76, de 25 de março de 1976. Portanto, ao tratar do Ibict, é impossível deixar de fazer uma alusão ao IBBD, órgão que lhe deu origem e, como tal, possui enormes ligações históricas. Assim, a agência nacional encarregada da política brasileira de informação científica e tecnológica já completou 51 anos.

Tanto o IBBD quanto o Ibict já foram objeto de estudos formais. Dentre eles, vale a pena destacar os de Maria Esther de Araújo Coutinho (1994), Antonio Agenor Briquet de Lemos (1986), Luiz Antonio Gonçalves da Silva (1987), Kira Tarapanoff (1992) e Jorge Luiz Santana (2001). Nesses cinco documentos, são analisados, entre outros, os contextos que motivaram a criação do IBBD, a sua transformação em Ibict, a imperiosa necessidade de formalização de uma política nacional de informação em ciência e tecnologia (ICT) e os objetivos desse órgão.

Parece que o maior fator de transformação do IBBD em Ibict foi o desejo de transformar essa nova agência em um órgão central que pudesse desempenhar, de forma descentralizada, as funções de coordenação das atividades de ICT. Para que essa coordenação fosse eficaz, o Ibict, no período de abril a setembro de 1984, promoveu um diagnóstico sobre a ampla área de ICT. Esse diagnóstico (Brasil, 1984) contou com a colaboração de mais de uma centena de participantes, e muitas de suas diretrizes ainda prevalecem até hoje.

Em 1985, com o advento da Nova República, foi criado o Ministério da Ciência e Tecnologia (MCT), que absorveu muitas das funções do Conselho Nacional de Desenvolvimento Científico e Tecnológico (CNPq). À semelhança do CNPq, órgão ao qual estava subordinado desde a sua criação em 1954, o Ibict passou a sofrer períodos de instabilidade, ocasionados principalmente pela sua mudança do Rio de Janeiro para Brasília, pela difícil implantação do novo ministério e pela falta de clareza a respeito dos rumos do CNPq. Inicia-se assim um período de difícil transição no qual se destaca a rotatividade de seus dirigentes. Tal fato pode ter ocasionado uma possível descontinuidade administrativa, com reflexos negativos nos diversos níveis da cadeia hierárquica, trazendo em seu bojo alguns transtornos, haja vista o novo perfil que cada dirigente trazia ao assumir, resultando em interrupção total ou parcial de projetos, ou na geração de novas ações sem uma adequada análise dos produtos/serviços e dos impactos resultantes, principalmente junto aos usuários potenciais.

No início da década de 90, com a crescente globalização da economia e o crescimento da Internet fora do âmbito acadêmico, o Ibict sofreu novo impacto. Surgiu um novo paradigma tecnológico, em que se destacam as novas redes de informação, muitas delas também em tempo real, o surgimento do periódico e da biblioteca digitais e a paulatina redução da intermediação da informação.

Em 2000, por meio do Decreto no 3.568 , de 17 de agosto, o Ibict passa a ser subordinado ao MCT, deixando o $\mathrm{CNPq}$, que havia perdido grande parte dos seus objetivos, tendo em vista a criação do ministério em 1985. Nesse mesmo período, o governo federal, por meio do Decreto no 3294/99, criou o Programa Sociedade da Informação (Socinfo), subordinado ao MCT. A partir daí, rumores começaram a aparecer sobre uma possível absorção do Instituto, ou até mesmo sobre sua extinção. Em 2002, com o Governo Lula, o Programa sofreu um esvaziamento, e muitas de suas funções foram redistribuídas para outros ministérios.

Mas o Ibict, agora com 51 anos, ainda é uma boa idéia? Respondemos que sim. É importante que o Estado brasileiro tenha uma agência que possa executar a coordenação da informação em ciência e tecnologia. Em um contexto tão dinâmico em que as organizações precisam adotar posturas proativas, o Instituto precisa identificar, de forma rápida e clara, as ameaças e oportunidades, recebendo insumos para que se possa fazer as devidas correções visando ao atendimento da sua missão organizacional. Espera-se que a informação em ciência e tecnologia possa ajudar na melhoria da qualidade de vida do brasileiro. Para tanto, o papel do Ibict é de suma importância.

\section{MURILO BASTOS DA CUNHA}

Universidade de Brasília

Departamento de Ciência da Informação e Documentação 


\section{REFERÊNCIAS}

BRASIL. Secretaria do Planejamento. Ação programada em ciência e tecnologia: informação em ciência e tecnologia. Brasília: Secretaria do Planejamento, Conselho Nacional do Desenvolvimento Científico e Tecnológico, Instituto Brasileiro de Informação em Ciência e Tecnologia, 1984. 69 p.

COUTINHO, Maria Esther de Araújo. A trajetória do Instituto Brasileiro de Bibliografia e Documentação (IBBD) de 1972 até a sua transformação, durante 1976, em Instituto Brasileiro de Informação em Ciência e Tecnologia (lbict). Brasília, Universidade de Brasília, Departamento de Ciência da Informação e Documentação, 1994. (Dissertação de Mestrado).

LEMOS, Antonio Agenor Briquet de. Planejamento e coordenação da informação científica e tecnológica no Brasil. Ciência da Informação, v. 15, n. 2, p. 107-116, jul./dez. 1986.
SILVA, Luiz Antonio Gonçalves. A institucionalização das atividades de informação científica e tecnológica no Brasil: o caso do Instituto Brasileiro de Bibliografia e Documentação (IBBD). Brasília: Universidade de Brasília, Departamento de Biblioteconomia, 1987.226 p. (Dissertação de mestrado).

TARAPANOFF, Kira. A política científica e tecnológica no Brasil: o papel do Ibict. Ciência da Informação, v. 21, n. 2, p. 87-166, maio/ago. 1992.

SANTANA, Jorge Luiz. O fluxo de informações para o apoio às decisões estratégicas na área de tecnologia da informação no Instituto Brasileiro de Informação em Ciência e Tecnologia (lbict). Brasília: Universidade de Brasília, Departamento de Ciência da Informação e Documentação, 2001. 161 p. (Dissertação de mestrado) 